EPJ Web of Conferences 110, 01006 (2016)

DOI: $10.1051 /$ epjconf/201611001006

(C) Owned by the authors, published by EDP Sciences, 2016

\title{
TECHNOLOGIES OF PHYSICAL MONITORING AND MATHEMATICAL MODELING FOR ESTIMATION OF GROUND FOREST FUEL FIRE CONDITION
}

\author{
Nikolay V. Baranovskiy ${ }^{1,}$ a and Alexandr V. Bazarov ${ }^{2}$ \\ ${ }^{1}$ National Research Tomsk Polytechnic University, 634050 Tomsk, Russia \\ ${ }^{2}$ Institute of Physical Material Science of the Siberian Branch of the Russian Academy of Science, Ulan-Ude, \\ Russian Federation
}

\begin{abstract}
Description of new experimental installations for the control of parameters of environment with a view of monitoring of forest fires presented in article. Stationary and mobile variants developed. Typical results of operation of installations during a fire-dangerous season of 2015 in vicinities of Ulan-Ude (Republic Buryatiya, Russia) presented. Onedimensional mathematical model of forest fuel drying which can be used for monitoring of forest fire danger with attraction of environmental parameters data during fire-dangerous season offered. Verification of mathematical model with use of known experimental data spent.
\end{abstract}

\section{Introduction}

Last years catastrophic natural fires cause an economic, ecological and social damage in various regions of our state and other countries of World community [1-4]. Following problems [5] can be selected in the field of forest protection from fires. First, an estimation and forecasting of forest fire danger level. Secondly, forecast of fire front distribution on a large forest. Thirdly, localization and suppression of the forest fires is problem too. Last problem is an estimation and liquidation of consequences of forest fires. The analysis of fire incidents in forests shows, that suppression of forest fires by modern means, as a rule, does not lead to success. Large forests or completely burn out to a meeting of front of forest fire with a natural barrier, or there is an attenuation of the forest fire to the beginning of rains season. Probably, that the most perspective is the approach of forecasting of forest fire danger on concrete forested territories for the purpose of development and carrying out of warning actions. The important process at forest fire danger beginning is drying of surface forest fuel under the influence of environmental conditions directly ahead of influence of local heating source [6-10].

By means of an offered hardware-software complex set of meteoconditions with humidity of soil as moisture content major factors [11-13] in forest fuel and air studied. Automatic measurement and registration of humidity and temperature of air, speed and a direction of a wind, quantity of liquid deposits and level of snow, humidity and temperature of soil by means of the registrar atmosphericsoil RAP-M-02 (mobile variant), a part atmospheric-soil measuring complex APIK-007 is spent. Registered time numbers of data form a basis for prognostic models of a prefire situation in forest

\footnotetext{
a Corresponding author: firedanger@yandex.ru
} 
environments. The given model can be used for monitoring of potentially fire-dangerous forest sites, especially at deficiency of the meteorological information.

\section{Experimental Installations}

The atmospheric-soil measuring complex contains on a ten-meters mast 1 (fig. 2), five gauges 2 of temperatures and humidity of air in radiating protection at heights $1,2,4,6$ and $10 \mathrm{~m}$, gauge 3 of speeds and wind direction, gauge 13 of total solar radiation, also solar battery 11 and aerial 12 for the modem of cellular communication which 6 registrars - the independent controller-logger (AKL) in the case. In a mobile variant on two-meters mast 1 located two gauges 2 of temperatures and humidity of air in radiating protection at heights 0,2 and gauge 13 of total solar radiation ( 2 channels) at $2 \mathrm{~m}$, gauge 3 of speeds and a direction of wind. Solar battery and cellular modem absent; power supply provided from 220 volt and accumulator with a stock of a charge for 2-5 months depending on season temperature; data transmission through USB provided. Near to a mast in each variant there is a gauge 4 of heights of snow cover and gauge 5 of liquid precipitations on two-meter tripod.

The soil part of stationary variant (fig. 2) for monitoring researches of soil modes contains a probe 9 profiles of temperature of a ground with digital gauges at levels $0 ; 2 ; 5 ; 10 ; 15 ; 20,25 ; 30,35 ; 40$; $45 ; 50 ; 55 ; 60 ; 80 ; 100 ; 120 ; 160 ; 240 ; 320 \mathrm{~cm}$ below soil surface. Basically, the length of a probe and quantity of gauges can change with monitoring conditions. The probe is executed in the form of the three-wire printed-circuit board with the high-precision digital thermometers soldered to it, the protected thermoshrinkable tube. For measurement of a profile of volume soil humidity some gauges 7 humidity of a ground intended. For measurement of conductivity of water provided the gauge 8 .

Probes of a profile of temperature in ground layer were presented in the form of four transitive boxes 10 with cables of five meters to logger in stationary and mobile variants (having on five digital single temperature gauges DS18B20 on half-meter wires for measurement of various adjusted temperature profiles of a ground on different depths from a surface). Also there are gauges 7 for humidity of ground (TRIME-PICO32) and 8 for conductivity of water were presented in installations. Control, gathering, accumulation and data transmission in variants 1,2 and 3 made by the registrar (AKL2 - GSM-modem), executed on the basis of microcircuits. In its case 6 is accumulator. The GSM-modem and the gauge of atmospheric pressure also located.

Test sites were limited by mineralized strips take places, each of which is filled by one of the most widespread forest fuel for the scenario in immediate proximity from installations. Controllable ignition of forest fuel for definition of ability of dry laying to ignition follows. Sites are equipped with fire extinguishing means by which the ignition centre will be neutralized. Experiment repeats to statistically significant set of cases.

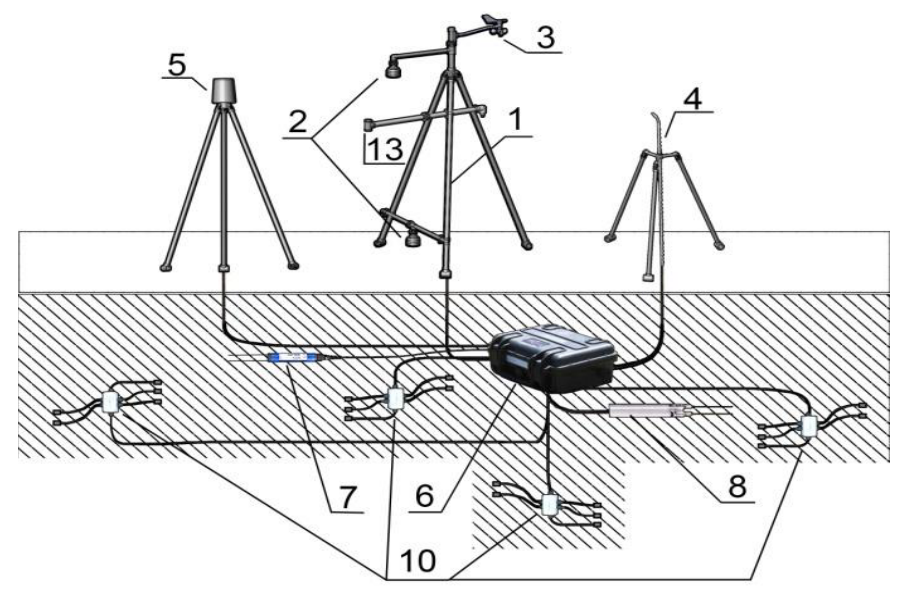

Figure 1. An atmospheric-soil measuring complex (mobile variant). 


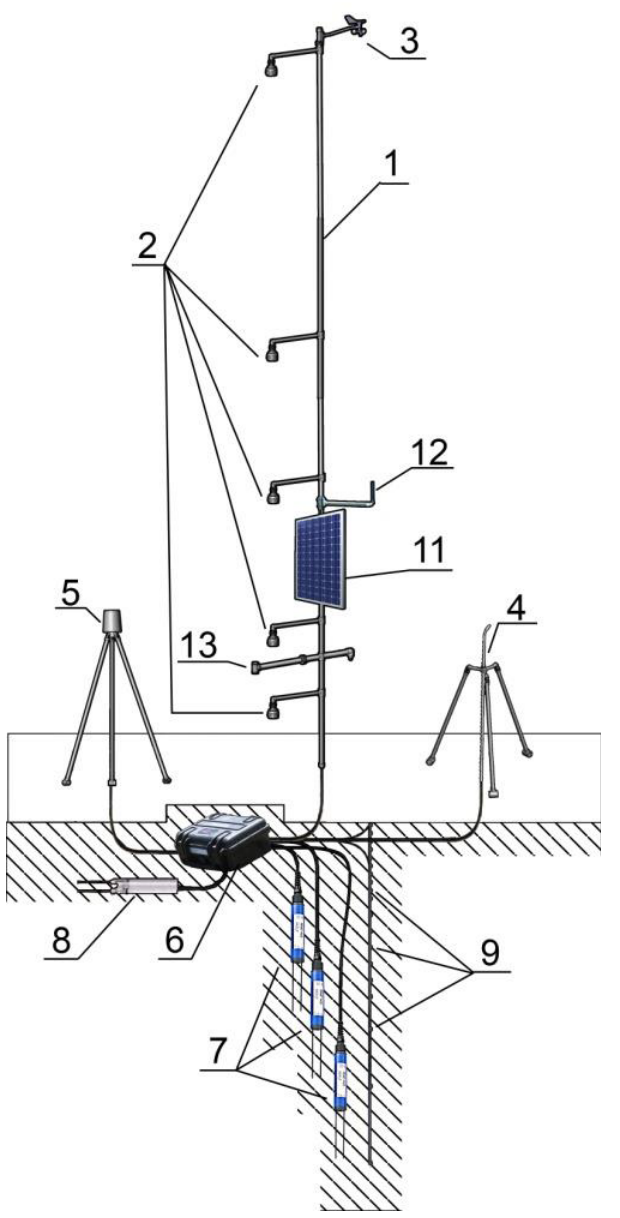

Figure 2. An atmospheric-soil measuring complex (stationary variant).

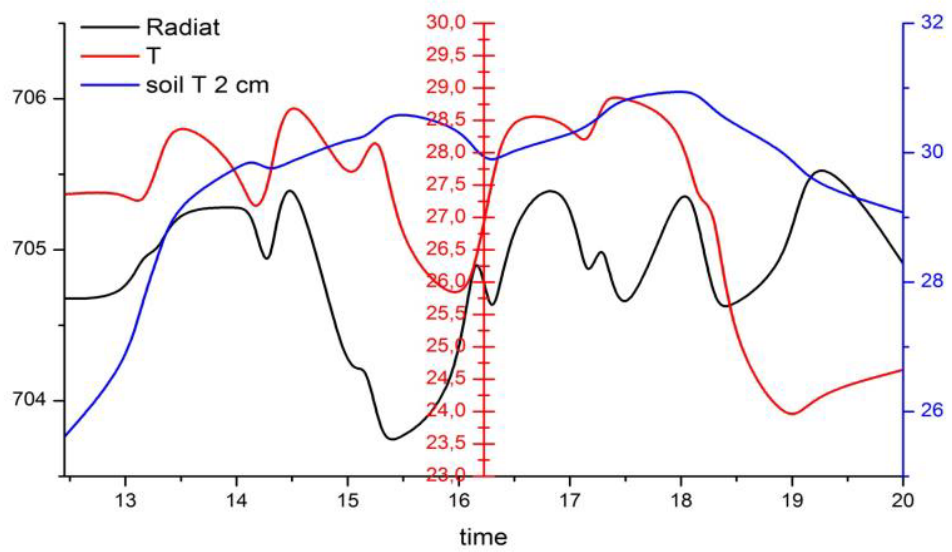

Figure 3. The typical data received from installation. On July, 21st, 2015. 
As a result of performance of works experimental installations of the control of parameters of environment (stationary and mobile variants) created. Pre-production operation of these installations in territory of large forest near to settlement Ulan-Ude (Buryatiya, Russia) spent. Data of observation which can be used at operation of the determined mathematical models of drying and ignition of forest fuel obtained.

\section{Mathematical Model of Forest Fuel Drying}

The fullest physical and mathematical model of forest fuel layer drying presented in work [14]. Various types of forest fuels in ground cover with heterogeneity of temperature and moisture content distribution considered. Two temperature approximation, radiation from the Sun, convectiveconductive heat exchange with a ground layer of atmosphere, water evaporation, partial pressure of water vapor taken into account. The problem reduced to system of the nonlinear differential equations of hyperbolic-parabolic type. Problem is complex (various variants on moisture content of different forest fuel layers). It is necessary to spend some hours for calculations of machine time on personal computer of IBM PC type that is absolutely not comprehensible and does not allows to use in the near future the given model into practice. The one-dimensional mathematical model of forest fuel drying under the influence of environmental conditions resulted [15]:

$$
\begin{aligned}
& \sum_{i=1}^{2} \rho_{i} \varphi_{i} \mathrm{C} p i \frac{\partial T_{S}}{\partial t}=\frac{\partial}{\partial z}\left(\lambda_{S} \frac{\partial T_{S}}{\partial z}\right)+\frac{\partial q_{R z}}{\partial z}-q_{2} \frac{k_{02}^{\prime} \rho_{2} \varphi_{2}}{\sqrt{T_{S}}}\left[\exp \left(-\frac{E}{R T_{S}}\right)-P_{2 e}\right]-\alpha_{v}\left(T_{S}-T_{e}\right) \\
& \rho_{1} \frac{\partial \varphi_{1}}{\partial t}=0 \\
& \frac{d \varphi_{2}}{d t}=-\frac{k_{02}^{\prime} \varphi_{2}}{\sqrt{T_{S}}}\left[\exp \left(-\frac{E}{R T_{S}}\right)-P_{2 e}\right] .
\end{aligned}
$$

Boundary conditions on the top and bottom borders of forest fuel layer register as follows [15]:

$$
\begin{aligned}
& -\left.\lambda_{s} \frac{\partial T_{s}}{\partial z}\right|_{z=h}=\alpha_{e}\left(T_{s w}-T_{e}\right)+q_{2} R_{2 w}-\varphi_{s w} q_{R w} \\
& \left.\lambda_{s} \frac{\partial T_{S}}{\partial z}\right|_{z=0}=\alpha_{0}\left(T_{s 0}-T_{0}\right)+q_{R w}\left(1-\varphi_{s w}\right) \exp \left(-k_{1} \rho_{1} h\right)
\end{aligned}
$$

Initial conditions for temperature, and volume moisture content become a volume fraction of dry organic substance [15]:

$$
\left.T_{s}(z)\right|_{t=0}=T_{s \mathrm{H}}(z),\left.\varphi_{1}(z)\right|_{t=0}=\varphi_{1 \mathrm{H}}(z),\left.\varphi_{2}(z)\right|_{t=0}=\varphi_{2 \mathrm{H}}(z)
$$

Where $\mathrm{z}$ - coordinate counted from a surface of soil of perpendicularly spreading surface; $\mathrm{t}$ - time; $\mathrm{T}_{\mathrm{s}}$ - temperature of the condensed phase (dry organic substance + free and connected water); $\lambda_{\mathrm{s}}$ factor of heat conductivity of the condensed phase in forest fuel layer; $\alpha_{e}$ - heat exchange factor on the top border of a layer; $\alpha_{0}$ - heat exchange factor on the bottom border of a layer; $T_{\mathrm{s} 0}$ - temperature of forest fuel layer on the bottom border of a layer; $\mathrm{T}_{\mathrm{e}}$ - ambient temperature; $\mathrm{T}_{0}$ - soil temperature; $\alpha_{\mathrm{v}}=$ $\alpha_{\mathrm{e}} \mathrm{S}$ - factor of volume convective heat exchange; $\rho_{\mathrm{i}}, \mathrm{C}_{\mathrm{pi}}, \varphi_{\mathrm{i}}$ - density, thermal capacities and volume 
fractions of dry organic substance $(\mathrm{i}=1)$ and water (free and connected with dry organic substance) $(\mathrm{i}=2) ; \lambda_{\mathrm{s}}=\lambda_{1} \varphi_{1}+\lambda_{2} \varphi_{2} ; \mathrm{k}_{02}^{\prime}$ - predexponent multiplier characterising evaporation of free and connected water; $\mathrm{E}$ - energy of activation characterising evaporation of free and connected water; $\mathrm{w}-$ moisture content; R - universal gas constant; $\varphi_{\mathrm{sw}}=\varphi_{1 \mathrm{w}}+\varphi_{2 \mathrm{w}}$ - volume fraction of the condensed phase on top border of forest fuel; $\mathrm{q}_{\mathrm{Rw}}$ and $\mathrm{q}_{\mathrm{Rz}}$ - flux of radiations on border of section of environments and flux of the radiation getting into forest fuel layer; $\mathrm{q}_{2}$ - heat effect of water evaporation; $\mathrm{k}_{1}$ - factor of attenuation of radiation in forest fuel layer; $\mathrm{P}_{2 \mathrm{e}}$ - partial pressure of water vapor; $h$ - thickness of forest fuel layer; $\mathrm{R}_{2 \mathrm{w}}$ - mass speed of evaporation of water on border of layer-environment.

Results of an experimental research of forest fuel drying presented in work [16]. Exiccators with sulfuric acid were used for creation of environment with changing relative humidity of air at a constancy of other factors. Following variants of carrying out of laboratory experiments have been accepted: ambient temperature was equaled $273 \mathrm{~K}, 293 \mathrm{~K}$ and $303 \mathrm{~K}$; relative humidity of air made 0 , 20, 40, 60, 80 and 90-100\%. Following intervals on time (in hours) were taken: 1, 2, 3, 4, 5, 7, 8, 24 etc. Each experience spent on three samples, thus the minimum error was equal to zero, and maximum $-1.15[16]$.

Results of numerical calculations and experimental data [16] on moisture content presented on fig. 4 .
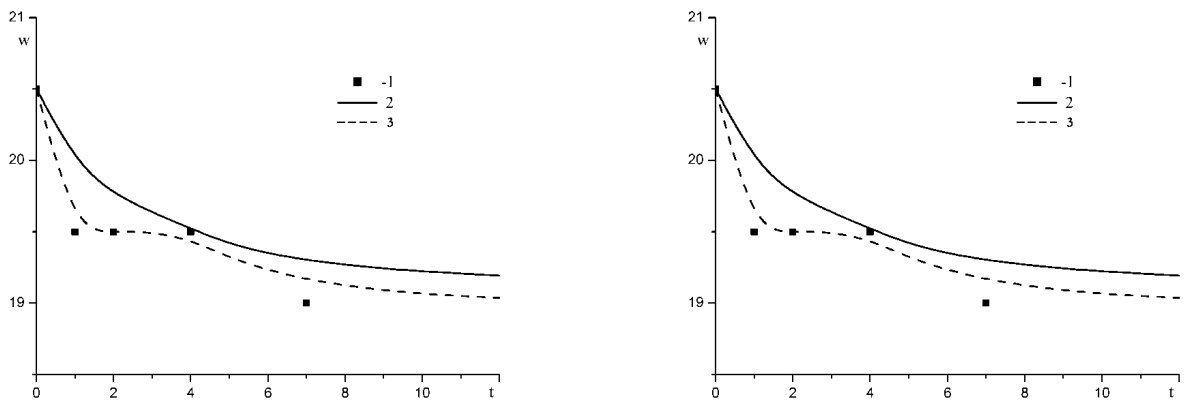

Figure 4. Dependence of forest fuel moisture content from time according to numerical calculations and experimental data [16]: 1 - experimental points; 2 - results of numerical calculation; 3 - a spline-approximation on experimental points; $\mathrm{T}_{\mathrm{e}}=273 \mathrm{~K}, \mathrm{w}_{\mathrm{i}}=20,5 \%$ and $\square_{\mathrm{e}}=80 \% ; 293 \mathrm{~K}, 24 \%$ and $60 \%$. w, \%, t, h.

The analysis shows, that there is good enough coordination of results of numerical calculation and experimental data [16]. The curves obtained numerically are close enough to the curves, found in result of spline-approximation of experimental data in most cases. The best coordination observed at the relative humidity of air close to $0 \%$, and small initial value of forest fuel moisture content. Accuracy of the description of experimental data by numerical modeling falls when growth the relative humidity and initial value of forest fuel moisture content.

\section{Conclusion}

Experimental installations of the environment parameters control (stationary and mobile variants) created as a result of research. Pre-production operation of these installations in territory of a large forest near to settlement Ulan-Ude (Buryatiya, Russia) spent. Data of supervision which can be used at operation of the determined mathematical models of drying and ignition of forest fuel layer obtained [17-19]. The hardware-software network of forest fire danger monitoring in controllable forest territories can be created on the basis of such installations and the software realizing of mathematical models of drying and ignition of forest fuel [20-23]. 


\section{References}

1. Kuznetsov G.V., Baranovskiy N.V. Forecast of occurrence of forest fires and their ecological consequences, (2009) (In Russian)

2. Wagtendonk J. W. Van. Fire as a physical process (Fire in California's ecosystems, 2006)

3. Flannigan M. D., Wotton B. M. Canadian Journal of Forest Research, 21, 277 (1991)

4. Larjavaara M., Kuuluvainen T., Rita H. Forest Ecology and Management, 208, 177 (2005)

5. Baranovskiy N.V. Thermophysical aspects of prognostic modeling of forest fire danger (Doctor dissertation, 2012) (In Russian)

6. Grishin A.M., Baranovskii N.V. Inzhenerno-Fizicheskii Zhurnal, 76, 166 (2003)

7. Reed W.J. Journal of Fire and Flammability, 1, 12 (1970)

8. Kuo J.T., Hsi C.L. Combustion and Flame, 142, 401 (2005)

9. Chan Park W., Atreya A., Baum H.R. Combustion and Flame, 157, 481 (2010)

10. Strezov V., Moghtaderi B., Lucas J. Journal of Thermal Analysis and Calorimetry, 72, 1041 (2003)

11. Garcia Diez E. L., Labajo Salazar J. L., De Pablo F. International Journal of Biometeorology, 37, 194 (1993)

12. Garcia Diez E. L., Rivas Soriano L., De Pablo F. Journal of Applied Meteorology, 33, 519 (1994)

13. Murphy A. H., Winkler R. L. Journal of American Statistical Association, 79, 489 (1984)

14. Grishin A.M., Golovanov A.N., Kataeva L.J., Loboda E.L. Combustion, Explosion and Shock Waves, 37, 57 (2001)

15. Grishin A.M., Kataeva L.Yu., Loboda E.L. Computational technologies, 6, 140 (2001) (In Russian)

16. Zhukovskaya V.I. Questions of forest pyrology (1970)

17. Kuznetsov G.V., Baranovsky N.V. EPJ Web of Conferences, 76, 01028 (2014)

18. Kuznetsov G.V., Baranovsky N.V., Barakhnin V.B. EPJ Web of Conferences, 82, 01019 (2015)

19. Baranovskiy N.V., Naumkin A.S. MATEC Web of Conferences, 19, 01036 (2014)

20. Baranovskiy N V. Cybernetics and Systems Analysis, 51, 471 (2015)

21. Baranovskiy N.V. Journal of Automation and Information Sciences, 47, 40 (2015)

22. Baranovskii N.V. Chemical and Petroleum Engineering, 51, 212 (2015)

23. Baranovskiy N.V., Yankovich E.P. Journal of Automation and Information Sciences, 47, 11 (2015) 